\title{
The judgment of covariation between binary variables: Some conditions that influence the process
}

\author{
IAN SEGGIE \\ The University of Newcastle, New South Wales, Australia
}

\begin{abstract}
Two hundred subjects made decisions based on the data of two binary variables, ethnic origin and employment status. They were asked to specify the information necessary and sufficient for making the decision before doing so. Variables studied were: (1) Type of question. Five questions were used, four of which focused on one of the four instances involved (e.g., Which information is necessary to find out if there is a connection between Asian immigrants and unemployment?). Question five was unbiased. (2) Type of variable. Half of the subjects found two symmetric variables, and half found one symmetric and one asymmetric variable. (3) Level of correlation. Five different correlations were used, three favoring Asians, one favoring Europeans, and one representing a zero correlation. Subjects made logical decisions that were not influenced by any of the experimental conditions. The selection of information before and after making choices was influenced by all variables except level of correlation. The biased questions produced deviations from normative reasoning; the two symmetrical variables and the process of making decisions encouraged normative reasoning.
\end{abstract}

One of the earliest attempts to replicate the work of Inhelder and Piaget (1958) in the field of covariation between binary variables was made by Smedslund (1963). In that study Smedslund asked nurses to examine the records of patients with respect to their status on a symptom and disease. From their examinations of the patients' records, the nurses were to describe to Smedslund the nature of the relationship between symptom and disease. All subjects were given 100 cards, each of which represented the record of a patient. The records showed that there were four different types of patient: (a) those who had both symptom and disease; (b) those who had no symptom but had the disease; (c) those who had the symptom but did not have the disease; and (d) those who had neither symptom nor disease. Each of these types may be represented in one cell $(a, b, c$, or $d)$ of the $2 \times 2$ contingency table.

The nurses examined the data under a variety of conditions, but Smedslund (1963) was unable to detect any ability on the part of his subjects to make any systematic approach to the data presented to them. From his report of the nurses' performance, it is clear that they were confused by the nature of the task. Smedslund was forced to the conclusion that his subjects did not have a cognitive structure isomorphic with the concept of correlation as outlined by Inhelder and Piaget (1958).

Since Smedslund's (1963) work, the ability of subjects to detect relationships between binary variables has been

The author thanks Alice F. Healy and two anonymous reviewers for their helpful comments and suggestions on the revision of an earlier version of this paper. Requests for reprints should be sent to Ian Seggie, Department of Psychology, The University of Newcastle, Shortland, New South Wales, 2308, Australia. studied under a number of conditions. Shweder (1977) and Nisbett and Ross (1980) were unequivocal in their interpretation of the evidence; they stated baldly that subjects do not have an intuitive understanding of the concept of correlation between dichotomous variables. More recently, Nisbett, Krantz, Jepson, and Kunda (1983) stated, "Rules of covariation assessment... are particularly difficult and may not even be represented in most people's repertoire"' (pp. 357-358). This echoed Peterson and Beach's (1967) earlier statement that subjects have special difficulties with the data of the $2 \times 2$ table.

However, in an extensive review of the literature, Crocker (1981) claimed "that Nisbett and Ross have overstated their case"' (p. 272). This claim was made on the basis of research showing that "under some circumstances people do understand the concept of covariation and use information about instances appropriately to estimate covariations"' (p. 282) (Alloy \& Abramson, 1979; Inhelder \& Piaget, 1958; Peterson, 1980; Ward \& Jenkins, 1965). In addition to that work, Green, Jurd, and Seggie (1979), Seggie (1975), Seggie and Endersby (1972), and Seggie and Schofield (1987) also reported conditions under which subjects make highly appropriate judgments of covariation between binary variables.

The failure of Smedslund's (1963) subjects to deal with the data of the $2 \times 2$ table in the laboratory stands in contrast to the successful applications of probabilistic reasoning in such fields as statistics, meteorology, and gambling. It was this apparent paradox that provoked Seggie and Endersby (1972) into specifying the logical implications of Smedslund's conclusions. They pointed out that if subjects do not have a cognitive structure isomorphic with the concept of correlation, then they would be incapable 
of utilizing the data of the $2 \times 2$ table in an empirical problem, the solution to which is embedded in the relationship between the binary variables of the table. Seggie and Endersby constructed such a problem, a decisionmaking task, which was presented to their subjects under conditions that paralleled as closely as possible those that faced Smedslund's nurses. Subjects were required to examine data that described a relationship between the location of the treatment for a disease (hospitalization or treatment at home) and the outcome of the treatment of past patients (recovery or failure to recover). They were required to prescribe the appropriate location for the treatment of a patient with the same disease. The task was found to be well within the ability of the subjects; this was reflected in the accuracy with which they made correct, logical decisions based on the data presented to them, similar to the data that had confused Smedslund's subjects. To make their decisions, subjects had to integrate the data of the four cells and estimate the approximate strength and direction of the correlation.

Since Seggie and Endersby's (1972) study, the decisionmaking task has been presented to a variety of subjects: army recruits, personnel employees, young and mature adolescents. The original findings have been replicated. Within the context of age and sex differences, subjects can use the binary relationships to make logical decisions. Although the decision making of subjects is less accurate when they are presented with data representing zero correlations (Green et al., 1979; Seggie, 1975; Seggie \& Endersby, 1972), the Green et al. study investigated the important consequences of the ceiling effect evident in the performance of subjects presented with correlated data. Green et al. pointed out that the decision-making task asks the subjects to make a choice between the two values of one variable, a choice that may encourage the search for a one-way causal relationship (e.g., a particular treatment leading to a particular outcome). However, to judge the relationship between two binary variables at a fully formal level, the two-way relationship must be considered. Green et al. showed that questions that ask subjects to make a judgment of the relationship between two binary variables encourage a higher degree of formal thought and, as a result, are more difficult than those that require subjects to make a choice on the basis of an assumed oneway relationship. Yet in the context of the present study, it is important to note that the decision-making task requires the utilization of the data of all four cells.

Nisbett and Ross (1980) and Seggie (1975) pointed out that a fully formed understanding of the relationship between binary variables necessarily involves an understanding of the relevance of the data of all four cells of the $2 \times 2$ table. However, accurate decision making on the basis of binary variables does not necessarily involve an understanding of the equality of importance of all four cells. A rating task was developed that required subjects to rate the strength of influence of the events of each cell following decision making. It has been found that sub- jects do not regard each cell as being equally important (Seggie, 1975; Seggie \& Schofield, 1987). Ratings were influenced by irrelevant variables, such as relative frequencies between cells or the salience of one of the variables. However, few subjects rated any of the four cells as having no influence in their decision making, a result that stands in contrast to the findings of Crocker (1982).

Crocker (1982) presented her subjects with a description of a covariation problem involving familiar variables: practicing or resting the day before an important tennis match and winning or losing the match. Subjects had to find out how the workout schedule affected match performance. They were presented a list of the four possible instances of the $2 \times 2$ table from the practicing/resting, winning/losing combinations and asked to specify which instances they would need to examine in order to make an accurate judgment about whether or not to work out the day before the match. The subjects were introduced to the task by one of three questions: the first specified the connection between working out and winning the match, the second specified the connection between working out and losing the match, the third was unbiased and specified the connection between "whether or not you work out the day before and whether or not you lose" (pp. 215-216). Crocker found that the instances specified by the subjects were a function of the question asked. Subjects presented the first question favored the selection of the practice/win information, those presented the second question favored the practice/lose information and subjects presented the third question required more overall information. Of importance is the fact that the majority of subjects under all conditions failed to specify all four types of information. Apparently these subjects believed that a rational judgment could be made on the basis of the data of only one, two, or three cells of the $2 \times 2$ table. However, the differences in performance between Seggie's (1975) and Crocker's (1982) subjects may have been the results of the demand characteristics of the tasks rather than an indication of the level of their thought processes.

A task that avoided these demands is reported by BeythMarom (1982), who presented her subjects with variables that could be related, such as skin color (dark/light) and temperature (high/low). The subjects were given statements describing the relationship between the variables (e.g., "There is a strong relationship between skin color and temperature') and asked to choose among five sentences representing possible interpretations of the relationship. Three of these involved less than three cells, and two involved all four cells. Her results indicated that the majority of her subjects "believed correlation is a function of all available information" (p. 516), that is, that all four cells of the $2 \times 2$ table were needed.

A comparison of Seggie's (1975), Beyth-Marom's (1982), and Crocker's (1982) tasks is of interest. In Seggie's rating task, the instructions directed the attention of the subjects to all four cells of the $2 \times 2$ table. Conse- 
quently, the majority of subjects ascribed each cell as having some importance in decision making. In the Crocker task, the instructions focused on individual cells of the table. This was a factor in the failure of Crocker's subjects to specify the events of all four cells. In the BeythMarom task, subjects were given a choice between sentences representing inadequate interpretations of the described relationship, those specifying the events of less than three cells, and those representing more adequate interpretations that specified the events of all four cells. The majority of students selected the adequate interpretations. It may well be that Crocker's subjects were aware of the relevance of all four events of the $2 \times 2$ table and that they would select them in the Crocker task under different conditions.

Beyth-Marom (1982) was concerned with the variability in research results involving people's understanding of correlation between dichotomous variables. She identified two factors in the literature that contributed to that variability and proposed a third. The existing two factors were data presentation and type of instruction; the proposed third was the type of variable, symmetric (e.g., high/low temperature) or asymmetric (e.g., present/absent symptom). This distinction is important, since the asymmetric variables are claimed to encourage focusing on one cell of the table at the expense of normative statistical reasoning.

In the case of an asymmetric variable, the two values may be seen as positive and negative or present and absent. One value of the variable may be seen as having less value than the other (e.g., the presence of a symptom is seen as being more salient than its absence). This problem does not exist with symmetric variables, the two values of which are seen as being equally important (e.g., a high temperature attracts as much attention from subjects as does a low one).

The present study was concerned with four issues derived from these studies. The first issue involved a replication of the decision-making task employing university students. Five levels of correlation were used. The second issue involved an extension of the Crocker (1982) task in which subjects were required to specify the information needed to make a judgment on a relationship between two binary variables. The extension involved the presentation of questions focusing on each of the four cells of the $2 \times 2$ table. The third and most important issue involved a development of the Crocker task in the context of the decision-making task. Before subjects can make logical decisions on the basis of the relationship between two binary variables, they must utilize the data of all four cells. The development involved asking subjects to specify the information they had used after making decisions. This allowed an examination of the possibility that experience in decision making could lead to a higher level of performance in the Crocker task. Finally, these issues were studied as a function of symmetric and asymmetric variables to investigate the claim by Beyth-Marom (1982) that the latter variables discourage normative reasoning.

\section{METHOD}

\section{Subjects and Procedure}

Two hundred first-year psychology students acted as subjects as part of their laboratory work. The experiment took place within the first 2 months of their university careers, before they had any contact with the formal study of statistics.

Subjects were introduced to the procedure with preliminary instructions that pointed to the fact that Australia, a country largely populated by immigrants, has an ongoing program of accepting new settlers based on government policy. They were asked to imagine that they were employed by the federal government at a fairly high level within the Department of Immigration. Part of their job was to study the results of government surveys and to make policy recommendations based on the findings of such surveys. In particular, the government was interested in the employment history of European and Asian immigrants as a means of facilitating particular employment policies. The task of the subjects was to examine the representative figures taken from a survey of employment records of recent immigrants and, on the basis of the survey, to recommend to the government one of three alternatives: (1) increase Asian immigration, (2) increase European immigration, or (3) neither. They did this by ticking the appropriate alternative from the three specified on a response sheet.

Before making the decision as to which alternative to recommend, subjects were asked to specify the information necessary and sufficient to their decision (the extension of the Crocker task). After making the decision, they were asked to specify the information they had actually used in deciding which recommendation to make (the development of the Crocker task). Three other factors were studied: type of question, symmetric/asymmetric variables, and level of correlation.

\section{Type of Question}

Before the decision-making task, subjects were asked to specify the information they regarded as necessary and sufficient to judge the relationship between the two events. The specified events differed for five groups of equal numbers of subjects within the symmetric and asymmetric conditions. Four of the groups read questions that referred to one cell of the $2 \times 2$ table; the fifth group read an unbiased question that referred to the two variables of the table. All questions for the five groups concluded as follows:

Put a tick beside the information that you think is necessary and sufficient to find out whether there is a relationship or connection....

1. (Focus on Cell $a$ ) between European immigrants and being employed (asymmetric).

between European immigrants and being self-employed (symmetric).

2. (Focus on Cell $b$ ) between Asian immigrants and being employed (asymmetric). between Asian immigrants and being self-employed (symmetric).

3. (Focus on Cell $c$ ) between European immigrants and being unemployed (asymmetric).

between European immigrants and working for someone else (symmetric).

4. (Focus on Cell $d$ ) between Asian immigrants and being unemployed (asymmetric)

between Asian immigrants and 
working for someone else (symmetric).

5. (Unbiased)

between ethnic group and employment status (symmetric and asymmetric).

Each subject selected one of these statements by ticking the appropriate boxes beside four statements describing the employment status of each ethnic group. Examples are: The number of Asian immigrants who were self-employed (Cell $b$; symmetric); the number of European immigrants who were unemployed (Cell $c$; asymmetric).

\section{Symmetric/Asymmetric Variables}

Half of the subjects learned that government policy was to favor the ethnic gorup that found employment more rapidly. The survey gave the frequency of employed and unemployed European and Asian immigrants at the end of their first 12 months of residence in Australia. The data showed that either European or Asian immigrants were more successful in finding employment, or that there was no difference between the ethnic groups. The $2 \times 2$ tables presented to these subjects contained an asymmetric variable (employed/unemployed) and a symmetric variable (European/Asian).

The instructions given to the remaining 100 subjects stated that government policy was to encourage immigration of the ethnic group whose individuals became successfully self-employed, the entrepreneurs. The survey gave the frequency of European and Asian immigrants who, at the end of 12 months, were self-employed and those who had become employees. The data could show that either European or Asian immigrants were more successful in becoming entrepreneurs, or that there was no difference. In this case both variables were symmetric (self-employed/employees and European/Asian).

\section{Level of Correlation}

Each subject made a recommendation on the basis of the frequencies within the four cells of a single $2 \times 2$ table. Five different correlations were used, and the subjects were distributed equally betwen the correlations, which are shown in Table 1 . The levels of correlation were calculated as the difference between $a / a+b$ and $c / c+d$ (Ward \& Jenkins, 1965).

\section{RESULTS}

\section{Decision Making}

From an examination of the data, it is evident that subjects made correct decisions with a high level of accuracy under both symmetric and asymmetric conditions. The results under these conditions were combined, and Table 2 shows the recommendations made by the subjects

Table 1

Frequencies of Instances in Cells $a, b, c$, and $d$ Under Five Different Levels of Correlation

\begin{tabular}{|c|c|c|c|c|c|}
\hline \multirow[b]{2}{*}{ Correlation } & \multicolumn{4}{|c|}{ Cell } & \multirow{2}{*}{$\begin{array}{l}\text { Value of } \\
\text { Correlation }\end{array}$} \\
\hline & $a$ & $b$ & $c$ & $d$ & \\
\hline 1 & 20 & 20 & 40 & 20 & -.17 \\
\hline 2 & 35 & 15 & 15 & 35 & .4 \\
\hline 3 & 20 & 40 & 20 & 20 & -.17 \\
\hline 4 & 15 & 35 & 35 & 15 & -.4 \\
\hline 5 & 60 & 20 & 30 & 10 & 0 \\
\hline
\end{tabular}

Note-Cell $a=$ European employed or self-employed; Cell $b=$ Asian employed or self-employed; Cell $c=$ European unemployed or employee; Cell $d=$ Asian unemployed or employee.
Table 2

Distribution of Decisions Made on Alternative Recommendations Under Five Levels of Correlation

\begin{tabular}{|c|c|c|c|c|}
\hline \multirow[b]{2}{*}{ Correlation } & \multicolumn{3}{|c|}{ Recommendations } & \multirow[b]{2}{*}{$\chi^{2}$} \\
\hline & Asian & European & Neither & \\
\hline 1 & 35 & 0 & 5 & $53.77 *$ \\
\hline 2 & 0 & 39 & 1 & $74.17^{*}$ \\
\hline 3 & 36 & 0 & 4 & $58.41 *$ \\
\hline 4 & 35 & 1 & 4 & $53.17 *$ \\
\hline 5 & 2 & 4 & 34 & $48.21 *$ \\
\hline
\end{tabular}

as a function of level of correlation. It is also evident that there is no difference in accuracy of decision making as a function of level of correlation and that a ceiling effect was in operation. The consequences of such an effect for the diagnosis of the subjects' level of thought were addressed by Green et al. (1979), who showed that accurate decisions can be made through the exercise of the penultimate level of formal operations. That subjects of the present experiment are at least capable of that level of thought in dealing with relationships beween dichotomous variables can be seen in Table 2 .

When the data showed that Asian immigrants were better at finding jobs or becoming self-employed, the subjects made the appropriate recommendations (correlations 1,3 , and 4, Table 1). When the data favored the European immigrants, the recommendations were likewise correct (Correlation 2, Table 1). Finally, when there was no relationship between ethnic group and occupational status, the subjects' understanding of the nature of the relationship was reflected in their decisions to recommend neither ethnic group (Correlation 5, Table 1).

\section{Selection of Cells Before and After Decision Making}

The subjects' nominations of cells before and after decision making were coded as follows: cell nominated $=1$; not selected $=0$. It was found that Lunney's (1970) criteria for the robustness of analysis of variance (ANOVA) applied to dichotomous data were satisfied. The proportion of responses in the smaller response category is greater than 0.2 , and the degree of freedom for error is greater than 40 . The data were analyzed by a mixed measures $5 \times 4 \times 2 \times 2$ ANOVA. The two between-subject variables were type of question and symmetric/asymmetric variables; the two within-subject factors were cell(s) selected and time (before and after decision making). No important differences in selection of cells were evident as a function of level of correlation; consequently that factor was not included in the ANOVA.

Two of the main effects were significant: cell(s) selected $[F(3,570)=50.21, M S \mathrm{e}=4.03, p<.00001]$ and time $[F(1,190)=40.16, M S \mathrm{e}=3.06, p<.00001]$. In addition, the following two-way interactions were significant: symmetric/asymmetric variables $\times$ cell(s) selected $[F(3,570)=8.86, M S \mathrm{Se}=0.71, p \geq .0001]$; 
Table 3

Proportion of Subjects in Each Condition Who Indicated the Information Necessary to Decision Making (Before) and That Had Been Used in the Process (After)

\begin{tabular}{|c|c|c|c|c|c|c|c|c|c|c|c|c|c|}
\hline \multirow{3}{*}{$\begin{array}{l}\text { Type of Information } \\
\text { (Asymmetric) }\end{array}$} & \multirow[b]{3}{*}{ Cell } & \multicolumn{12}{|c|}{ Question Focus } \\
\hline & & \multicolumn{2}{|c|}{$a$} & \multicolumn{2}{|c|}{$b$} & \multicolumn{2}{|c|}{$c$} & \multicolumn{2}{|c|}{$d$} & \multicolumn{2}{|c|}{ Unbiased } & \multicolumn{2}{|c|}{ Marginal } \\
\hline & & Before & After & Before & After & Before & After & Before & After & Before & After & Before & $\overline{\text { After }}$ \\
\hline European Employed & $a$ & .95 & .90 & .55 & .90 & .85 & .95 & .30 & .90 & .65 & .60 & .66 & .85 \\
\hline Asian Emp & $b$ & .50 & .95 & .95 & .90 & .50 & .85 & .90 & .75 & .65 & .80 & .70 & .85 \\
\hline European Unemployed & $c$ & .60 & .60 & .30 & .45 & .95 & .55 & .60 & .30 & .60 & .45 & .61 & .47 \\
\hline Asian Une & $d$ & .30 & .60 & .50 & .55 & .35 & .60 & 1.00 & .50 & .45 & .40 & .52 & .53 \\
\hline Marginal & & .68 & & .64 & & .70 & & .66 & & .58 & & & \\
\hline
\end{tabular}

Note-All $n s=20$.

type of question $\times$ cell(s) selected $[F(12,570)=17.30$, $M S \mathrm{e}=1.39, p<.0001]$; symmetric/asymmetric variables $\times$ time $[F(1,190)=6.43, M S e=0.49, p<.01]$; type of question $\times$ time $[F(4,190)=11.37, M S e=0.87$, $p<.00001]$; and cell(s) selected $\times$ time $[F(3,570)=$ 21.06, $M S \mathrm{e}=1.54, p<.00001]$.

The Tukey post hoc test was used to compare the differences between the means. The significant cell(s) selected factor stemmed from the higher selection of Cells $a$ and $b$ as opposed to Cells $c$ and $d$. The instances of Cell $d$ were also selected at a significantly lower level than those of Cell $c$. The significant time factor stemmed from an increase in the number of cells selected after the decisionmaking task. The interactions of the main effects can be examined from a comparison of the results shown in Tables 3 and 4.

Symmetric/asymmetric variables $\times$ cell(s) selected. Under both conditions subjects selected $a$ and $b$ cells more frequently than $c$ and $d$. However, there was a significant difference in the selection of the $c$ and $d$ cells between symmetric and asymmetric conditions. Subjects given symmetric variables selected the $c$ and $d$ cells at a significantly higher frequency than did subjects given asymmetric variables.

Type of question $\times$ cell(s) selected. Questions that focused on the events of a particular cell led to a higher selection of the specified cell. In addition, it can be seen that the unbiased question resulted in less variability between the cells selected.

There is also evidence that before decision making subjects tended to focus on the specified ethnic status rather than on the employment status. The question that focused on Cell $a$ led to a higher selection of Cell $c$; the recipro- cal is true for the question that focused on Cell $c$. The question that focused on Cell $b$ led to a higher selection of Cell $d$; the reciprocal is true for the question that focused on Cell $d$.

Symmetric/asymmetric variables $\times$ time. Significantly more selections were made after decision making. The interaction stemmed from the increase in selections of subjects working with symmetric variables who selected relatively more cells than did the subjects asked to examine asymmetric variables.

Type of question $\times$ time. The relative increase as a function of time varied with the questions. Focus on Cells $a$ and $c$ produced the largest increase in selections. In the context of the type of question $\times$ cell(s) selected interaction, it is of no small interest that the increase came largely from the greater selection of Cells $b$ and $d$, the cells largely neglected before decision making.

The fact that there was no increase as a function of time when the question was unbiased also contributed to this interaction.

Cell(s) selected $\times$ time. Before decision making, subjects made significantly higher selection of Cells $a, b$, and $c$ than of $d$. After decision making, there was a significant increase in the selection of Cells $a$ and $b$, which led to a significantly higher selection for these cells as opposed to Cells $c$ and $d$.

Also of interest is the data of Table 5, which shows the number of subjects who selected all four cells before and after decision making (Column 1), compared with those who (1) selected less than four cells before and all four cells after decision making (Column 2), (2) selected less than four cells before and after decision making but made an increase in the number of cells selected after decision

Table 4

Proportion of Subjects in Each Condition Who Indicated the Information Necessary to Decision Making (Before) and That Had Been Used in the Process (After)

\begin{tabular}{|c|c|c|c|c|c|c|c|c|c|c|c|c|c|}
\hline \multirow{3}{*}{$\begin{array}{l}\text { Type of Information } \\
\text { (Symmetric) }\end{array}$} & \multirow[b]{3}{*}{ Cell } & \multicolumn{12}{|c|}{ Question focus } \\
\hline & & \multicolumn{2}{|c|}{$a$} & \multicolumn{2}{|c|}{$b$} & \multicolumn{2}{|c|}{$c$} & \multicolumn{2}{|c|}{$\bar{d}$} & \multicolumn{2}{|c|}{ Unbiased } & \multicolumn{2}{|c|}{ Marginal } \\
\hline & & Before & After & Before & After & Before & After & Before & After & Before & After & Before & After \\
\hline European Self-employed & $a$ & .75 & .80 & .75 & .95 & .75 & .90 & .40 & .85 & .80 & .70 & .69 & .84 \\
\hline Asian Self-employed & $b$ & .35 & .70 & .85 & 1.00 & .25 & .85 & .70 & .80 & .90 & .75 & .61 & .82 \\
\hline European Employed & $c$ & .70 & .80 & .70 & .60 & .80 & .60 & .60 & .75 & .65 & .75 & .69 & .70 \\
\hline Asian Employed & $d$ & .20 & .65 & .75 & .60 & .20 & .55 & .85 & .75 & .65 & .70 & .53 & .65 \\
\hline Marginal & & .62 & & .78 & & .61 & & .71 & & .74 & & & \\
\hline
\end{tabular}

Note-All $n s=20$. 
Table 5

Frequency of Subjects' Selections

\begin{tabular}{lccccc}
\hline Variable & 1 & 2 & 3 & 4 & $N$ \\
\hline Asymmetric & 13 & 27 & 4 & 56 & 100 \\
Symmetric & 27 & 29 & 11 & 33 & 100 \\
Total & 40 & 56 & 15 & 89 & 200 \\
\hline
\end{tabular}

Note-Frequency of subjects selecting: 4 cells before and after decision making (Column 1); less than 4 cells before, all 4 cells after decision making (Column 2); less than 4 cells before and after decision making but increasing number of cells after decision making (Column 3); and same number of cells before and after decision making (Column 4). $\quad \chi^{2}(3, N=200)=14.17, p<.01$.

making (Column 3), and (3) made no change in the number of cells selected (Column 4). Table 5 compares the statistically significant departure from a random distribution of subjects as a function of symmetric/asymmetric variables. Columns 1, 2, and 3 are of particular interest.

From Column 1 it can be seen that of the subjects who were presented with an asymmetric variable, only 13 nominated all four cells before decision making. This contrasts with the 27 subjects given symmetric variables who selected all four cells. The difference is significant $\left[\chi^{2}(1, N=40)=4.9, p<.05\right]$.

Column 2 of Table 5 shows the number of subjects who selected all four cells after decision making, having failed to do so before. The figures of that column show two important phenomena. First, the difference in Column 1 as a function of symmetric/asymmetric variables has disappeared. Second, and perhaps more important, the 56 subjects of Column 2 are those who improved the level of their cognitive functioning as a function of the decisionmaking process.

The 15 subjects of Column 3 increased their selections of cells from one to two or three, or from two to three. Although this may represent a tentative move toward the realization of the relevance of all data, the evidence is more equivocal. But again the influence of the symmetric/asymmetric variable is seen, and it is the symmetric variable that is associated with the larger number of subjects who could have made such a move.

\section{DISCUSSION}

\section{Decision Making}

The results replicated the earlier studies by Seggie and his colleagues and extends the population sample that has shown facility in detecting the relationship between binary variables in the context of an empirical task. Clearly, the performance of the subjects supports the statement that "under some circumstances people do understand the concept of correlation" (Crocker, 1981, p. 282). Of interest are the conditions that allow the diagnosis of that understanding and the nature of the knowledge at the base of the understanding.

Crocker (1981) specified the various statistical alternatives that may be used to calculate the degree of covari- ation between binary variables. Of the hundreds of subjects who have performed successfully in the decision-making task, none has had any formal knowledge of these methods. But all have had the basic arithmetical knowledge of the operations of addition, subtraction, and division. Green et al. (1979) showed that the decisionmaking task imposes a ceiling effect, in that success is possible through the use of these basic arithmetical operations in a one-way comparison of proportions, such as $a / c$ to $b / d$ or $a / a+b$ to $c / c+d$. They make the point that this does not involve the precise calculation of the mathematical figure representing the correlation, as do Seggie and Endersby (1972).

In the context of the present results, a consequence of the ceiling effect is that there were no differences in the accuracy of decision making as a function of symmetric/asymmetric variables or level of correlation. Clearly, the conditions of the experiment encouraged normative reasoning in judging the relationship between binary variables. Previous studies also have shown that asymmetric variables discourage such reasoning by drawing the attention of subjects to the events of the "positive" cells at the expense of the remainder of the data (Beyth-Marom, 1982). Although that has occurred in the selection of cells before and after decision making, it has not interfered with the operations of the subjects during decision making.

Previous studies have shown that there is an increase in errors when subjects have to deal with zero correlations or relationships having nonsymmetric frequencies within the cells of the $2 \times 2$ table (Green et al., 1979; Seggie, 1975; Seggie \& Endersby, 1972). That has not occurred in the present experiment. The efficiency of the subjects' thought processes highlights the opposite side of the coin referred to by Crocker (1981) when she pointed to the vulnerability of subjects to influences that make them deviate from the appropriate use of evidence. There may also be factors that sensitize subjects to the appropriate use of evidence. Such a factor may have been operative in the performance of the present subjects, a factor that could have stemmed from community concerns that were evident at the time of data collection.

At that time a national debate was in progress as a result of calls on the part of prominent people for an examination of the ethnic origin of new settlers. Although an attempt was made to contain the emotive potential involved in such a debate, it was not wholly successful. Extremist political minorities were quick to attack minority ethnic groups on racial grounds. In that context, the variables used may have provoked in subjects an acute awareness of the need to be scrupulously fair in their recommendations, with a consequent focus on the relevant data to the exclusion of irrelevant factors.

Although such an explanation is necessarily speculative, the fact of the subjects' performance is not. Neither are the explanations of the basic abilities of subjects to detect covariation between binary variables. The present 
results are part of a growing body of evidence indicating that subjects do have an understanding of the relationship involved. To claim that subjects do not have an intuitive understanding of the concept of correlation is to continue to ignore that body of evidence. There may well be particular difficulties for subjects; the evidence is growing that the source of these difficulties may lie in the field of experimental design and psychological diagnostics (Smedslund, 1969), rather than any innate lack of ability in the subjects. The task is one of finding the conditions that will encourage normative reasoning and formal thought (Halford, 1972; Nisbett et al., 1983). The fluidity of these thought processes can be seen in the subjects' selections of cells.

\section{Selection of Cells Before and After Decision Making}

Crocker (1982) asked her subjects three types of question: one focused on the events of Cell $a$, a second focused on Cell $b$, and a third was unbiased. These questions were used in the present experiment, together with an additional two focusing on Cells $c$ and $d$. The results of the present study closely replicate Crocker's work and show that the biasing effect of the questions extends to Cells $c$ and $d$. In addition, the results point to another source of bias. More important, the development of the Crocker task indicates that subjects may be sensitized to normative reasoning through the use of appropriate conditions.

The additional source of bias is of interest in the context of the claim that the ceiling effect in decision making might have stemmed from the subjects' sensitivity to ethnic issues. This sensitivity is reflected in subjects' choices before decision making. When Crocker's (1982) subjects were presented with a question focusing on Cell $a$, they made significantly more selections of that cell exclusively. Similarly with Cell $b$. But when the subjects of the present experiment were presented with a question focusing on Cell $a$, they made significantly more selections of Cells $a$ and $c$. When presented with a question focusing on Cell $b$, they made significantly higher selections of Cells $b$ and $d$. The same effect was evident in questions focusing on Cells $c$ and $d$.

Although Crocker's (1982) subjects were biased toward one cell, the subjects of the present experiment were biased in favor of two, either $a$ and $c$ or $b$ and $d$. This reflects their sensitivity toward the variable of ethnic status rather than employment status. Cells $a$ and $c$ gave information on Europeans, and Cells $b$ and $d$ gave information on Asians.

The claim that the variable of ethnic status may have made the subjects more sensitive to the appropriate use of evidence is supported by the effect of the level of correlation variable. This had no effect on the subjects' performance in either decision making or selection of cells. For example, in Correlations 1 and 3 only one cell differs from the remaining three ( $c$ and $b$, respectively). Previ- ous work has shown that subjects are influenced by frequency of instances (Crocker, 1981). That influence might have been reflected in the patterns of cell selections after decision making. It was not. Subjects were more sensitive to ethnicity.

In addition to revealing a bias toward the ethnic variable, the selections indicate that, prior to decision making, subjects believed that recommendations could be made based on the data of one ethnic group only. However, the effect of the decisions in promoting normative reasoning can be seen in the significant time factor and its interaction with symmetric/asymmetric variables, questions, and cells.

Subjects selected a greater number of cells when asked to indicate the cells they had used in decision making. Presentation of the symmetric variable resulted in higher frequency of selection. Questions that focused on Cells $a$ and $c$ before decision making resulted in a greater selection of $b$ and $d$ after decision making.

However, the clearest evidence of the procedure inducing normative reasoning can be seen in Table 5 . The 56 subjects of Column 2 selected less than four cells before decision making but selected all four afterward. It would appear that making decisions involving all four cells has raised the level of thought of these subjects. This may also be true of the subjects of Column 3 . That change could not have been predicted from the work of Brehmer (1980), who claimed that it is rare for subjects to improve judgments as a result of experience.

Yet from Column 4 it can be seen that close to $50 \%$ of the subjects did not have access to their thought processes, in that they were unaware that they had used all four cells in making their judgments. The performance of these subjects would have been predicted from the work of Nisbett and Wilson (1977), who claimed that subjects do not normally have access to their thought processes.

The findings of the present experiment would support the statements by Halford (1972) and Nisbett et al. (1983) that an important area of investigation lies in mapping the conditions that encourage formal thought and statistical reasoning. Since Smedslund's (1963) seminal paper, the mass of the work done on formal operational thought indicates that the development of such thought processes does not proceed spontaneously or automatically (Seggie, 1978).

In the case of understanding the relationship between binary variables, formal thought involves an appreciation of the involvement of all four cells. Procedures that discourage focusing on less than four cells may well encourage such understanding. Conditions that provoke the algorithmic application of basic and well-rehearsed arithmetical operations is one such procedure. But it is evident that the search for the conditions that promote formal thought must be made in the awareness of the fluidity of these thought processes which reflects the capacity for regression as a function of numerous factors. 


\section{REFERENCES}

Alloy, L. B., \& AbRamson, L. Y. (1979). Judgment of contingency in depressed and nondepressed college students: Sadder but wiser? Journal of Experimental Psychology: General, 108, 441-485.

Beyth-Marom, R. (1982). Perception of correlation reexamined. Memory \& Cognition, 10, 511-519.

BREHMER, B. (1980). In one word: Not from experience. Acta Psychologica, 45, 223-241.

Crocker, J. (1981). Judgment of covariation by social perceivers. Psychological Bulletin, 90, 272-292.

Crocker, J. (1982). Biased questions in judgment of covariation studies. Personality \& Social Psychology Bulletin, 8, 214-220.

GreEn, S., JURD, M., \& SEgGIE, J. L. (1979). Formal thinking about correlation. Scandinavian Journal of Psychology, 20, 119-125.

HALFoRD, G. S. (1972). The impact of Piaget on psychology in the seventies. In P. C. Dodwell (Ed.), New horizons in psychology 2. London: Penguin.

INHELder, B., \& Piaget, J. (1958). The growth of logical thinking from childhood to adolescence. London: Routledge \& Kegan Paul.

LUNNEY, G. H. (1970). Using analysis of variance with a dichotomous dependent variable: An empirical study. Journal of Educational Measurement, 4, 263-269.

Nisbett, R. E., Krantz, D. H., Jepson, C., \& Kunda, Z. (1983). The use of statistical heuristics in everyday reasoning. Psychological Review, 90, 339-363.

NisBeTt, R., E., \& Ross, L. (1980). Human inferences: Strategies and shortcomings of social judgment. Englewood Cliffs, NJ: Prentice-Hall.

NisBeTt, R. E., \& Wilson, T. D. (1977). Telling more than we can know: Verbal reports on mental processes. Psychological Review, 84, 231-259.
Peterson, C. (1980). Recognition of noncontingency. Journal of Personality \& Social Psychology, 38, 727-734.

Peterson, C. R., \& BeACH, L. R. (1967). Man as an intuitive statistician. Psychological Bulletin, 68, 29-46.

SEGGie, J. L. (1975). The empirical observation of the Piagetian concept of correlation. The Canadian Journal of Psychology, 29, 32-42.

SEGGIE, J. L. (1978). Formal operational thought. In J. A. Keats, K. F. Collis, \& G. S. Halford (Eds.), Cognitive development: Research based on a neo-Piagetian approach (pp. 349-388). Chichester: Wiley.

SEGGIE, J. L., \& ENDERSBY, H. (1972). The empirical implications of Piaget's concept of correlation. Australian Journal of Pychology, 24, 3-8.

SEGGIE, J. L., \& SCHOFIELD, M. (1987). The development of adolescents' intuitive logic in decision making on the basis of binary variables. Manuscript submitted for publication.

SHWEDER, R. A. (1977). Likeness and likelihood in everyday thought: Magical thinking and everyday judgments about personality. In P. N. Johnson-Laird \& P. C. Wason (Eds.), Thinking: Readings in cognitive science. Cambridge: Cambridge University Press.

SmedsLund, J. (1963). The concept of correlation in adults. Scandinavian Journal of Psychology, 4, 165-173.

SMedslund, J. (1969). Psychological diagnostics. Psychological Bulletin, 71, 237-248.

WARD, W. C., \& JENKINS, H. M. (1965). The display of information and the judgment of contingency. The Canadian Journal of Psychology, 19, 231-241.

(Manuscript received December 19, 1985; revision accepted for publication October 27, 1986.) 